Www.jmscr.igmpublication.org

Impact Factor (SJIF): 6.379

Index Copernicus Value: 79.54

ISSN (e)-2347-176x ISSN (p) 2455-0450

crossrefDOI: https://dx.doi.org/10.18535/jmscr/v6i10.30

Journal Of Medical Science And Clinical Research

\title{
Diagnostic Usefullness of Trucut Biopsy in Diagnosis of Palpable Breast Lesions
}

\author{
Authors \\ Malika Mehta' ${ }^{1}$, S. V Jagtap ${ }_{1,2,3}$, Dhruv Aggarwal ${ }^{3}$, Pearl Aggarwal ${ }^{4}$ \\ ${ }_{1,2,3}$ KIMSDU, ${ }^{4}$ SGT University
}

\begin{abstract}
Introduction: Tru-cut biopsy is now one of the useful means of obtaining early and accurate histopathological diagnosis. It is easy and can be performed on an outpatient basis. It also avoids unnecessary excisional biopsy. It provides sufficient amount of tissue for pathologist to make an accurate histological diagnosis with its type, grade and degree of differentiation in majority of cases

Aim: To study usefullness of trucut biopsy of palpable breast lesions in patients coming to a tertiary care hospital

Objectives: 1. To correlate findings of trucut biopsy with histopathology of follow up surgical procedures.

2. To find sensitivity, specificity, positive predictive value, negative predictive value and overall diagnostic accuracy of trucut biopsy.

Material and Methods: A prospective comparitive study of two years conducted in Department of Pathology KHMRC between June 2015 to June 2017. The study includes 106 patients of palpable breast lump. Trucut biopsy was performed using a Tru-Cut gun BARD MAX-CORE with an 18-gauge needle by means of 4 successive insertions with different angulations of the needle into the lesion's core.

Result: The study includes 106 patients, Trucut Biopsy findings correlated with the histopathological findings in 103 of 106 cases (97.2\%), which included 29 of 30 (96.7\%) of the benign lesions and 74 of 76 (97.4\%) of the malignant lesions.

Conclusion: Tru-cut biopsy is an easy, cost-effective, safe and accurate in diagnosing breast lesions and in detecting suspicious malignant breast lumps It is also superior to open biopsy in terms of safety, hospital stay, costs, post operative pain and complications.
\end{abstract}

\section{Introduction}

Tru-cut biopsy of palpable breast lesions can provide all the reliable information to guide the surgeon and the oncologist to plan an ideal therapeutic strategy in surgical decision making. ${ }^{1}$ And permits the eventual use of neoadjuvant therapy. ${ }^{2}$ On the other hand excisional biopsy would provide the pathologist with the whole breast lesion and allows him or her to examine its histopathological type, grade and degree of differentiation of the carcinoma if present. Also receptor status for estrogen, progesterone and tyrosine kinas Her2 (C erb b2) can be assessed. However, it mostly requires general anesthesia. ${ }^{3,4}$

\section{Aim}

To study usefullness of trucut biopsy of palpable breast lesions in patients coming to a tertiary care hospital 


\section{Objective}

1. To correlate findings of trucut biopsy with histopathology of follow up surgical procedures.

2. To find sensitivity, specificity, positive predictive value, negative predictive value and overall diagnostic accuracy of trucut biopsy.

\section{Material and Methods}

A prospective comparative study of two years conducted in Department of Pathology KHMRC. between June 2015 to June 2017. The study includes 106 patients of palpable breast lump. Trucut biopsy was performed using a Tru-Cut gun BARD MAX-CORE with an 18-gauge needle by means of 4 successive insertions with different angulations of the needle into the lesion's core.

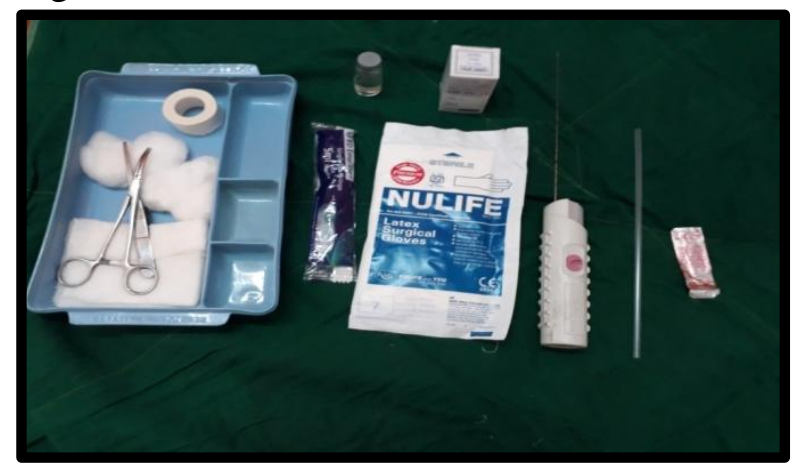

Figure-1- Equipments required for trucut procedure

\section{Result and Discussion}

In the present study, majority of the patients $(30.2 \%)$ were in the age group of $41-50$ years followed by $23.6 \%$ in the age group of $51-60$ years, $19.8 \%$ in the age group of $31-40$ years, $14.2 \%$ in the age group of $21-30$ years and $12.2 \%$ in the age group of $>60$ years. The most common clinical presentation in our study was a lump (90.7\%) which was not associated with any other complaint (pain/ulcer) The left breast was affected in $52(49 \%)$ patients while the right breast was affected in $53(50 \%)$ patients. Bilateral involvement was observed in $1(1 \%)$ patient. In maximum cases $(60.4 \%)$, the lump measured between $3-5 \mathrm{cms}$ while in minimum $(5.7 \%)$ cases, it measured $<3 \mathrm{cms}$.

Table-1 Distribution of breast lesions on Trucut biopsy according to different $\mathrm{CNB}$ categories

\begin{tabular}{|c|c|c|}
\hline Category & $\mathbf{N}$ & $\mathbf{\%}$ \\
\hline B1 & 0 & - \\
\hline B2 & 30 & $28.2 \%$ \\
\hline B3 & 0 & - \\
\hline B4 & 1 & $0.9 \%$ \\
\hline B5 & 75 & $70.7 \%$ \\
\hline Total & 106 & $100 \%$ \\
\hline
\end{tabular}

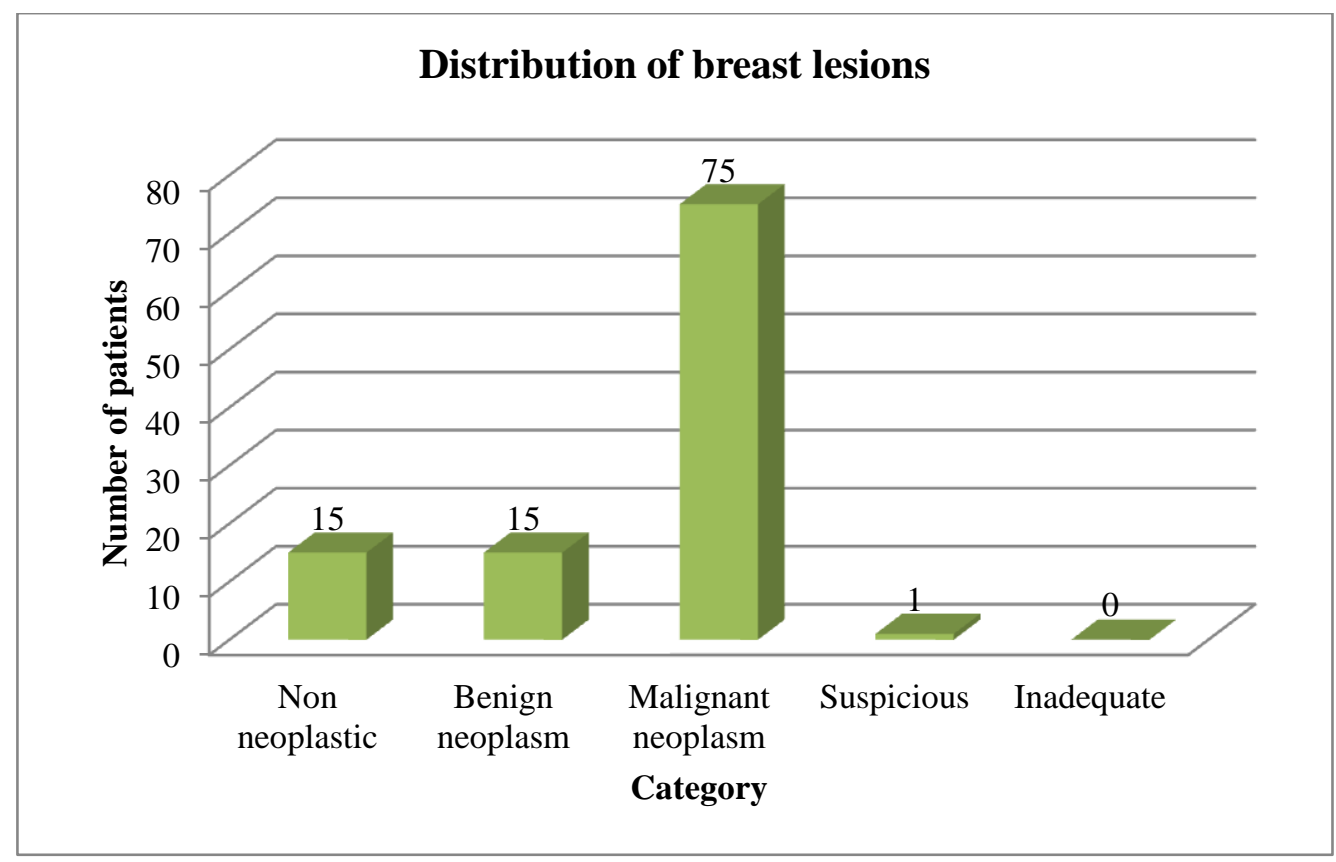

Figure 2 Distribution of breast lesions on Trucut biopsy 


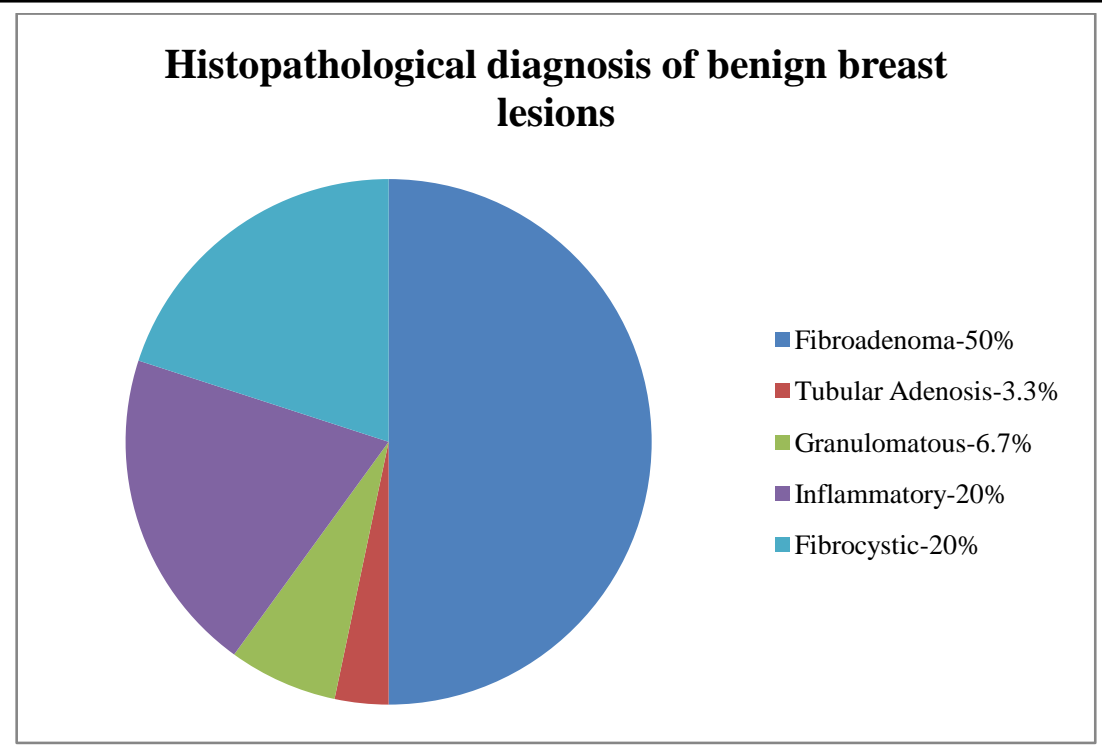

Figure-3 Histopathological diagnosis of benign breast lesions

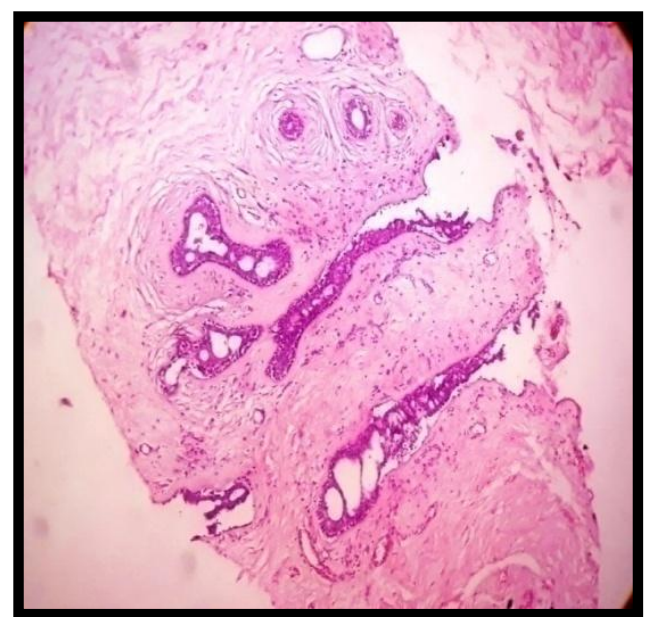

Figure-4 Photomicrograph of needle core biopsy showing Fibroadenoma (H\& E stain,100x)
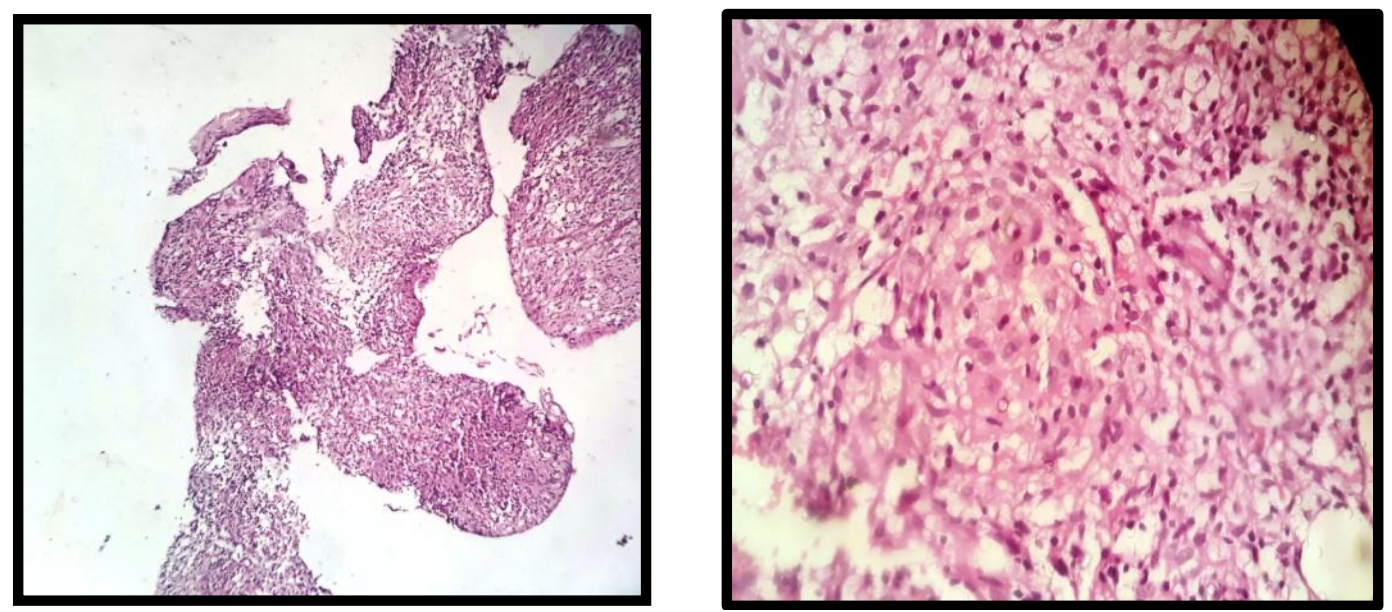

Figure-5,6 The needle core biopsy shows features of non specific Granulomatous Mastitis (H \& Estain, $40 x \& 400 x)$ 


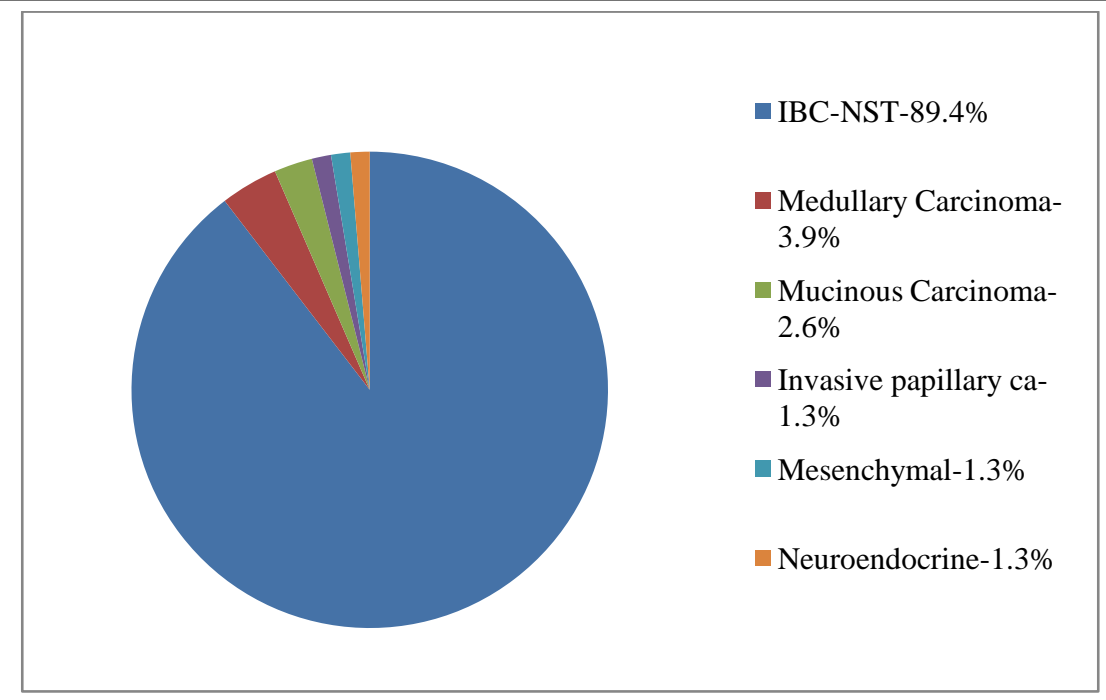

Figure 7: Histopathological Diagnosis of Malignant Breast Lesions
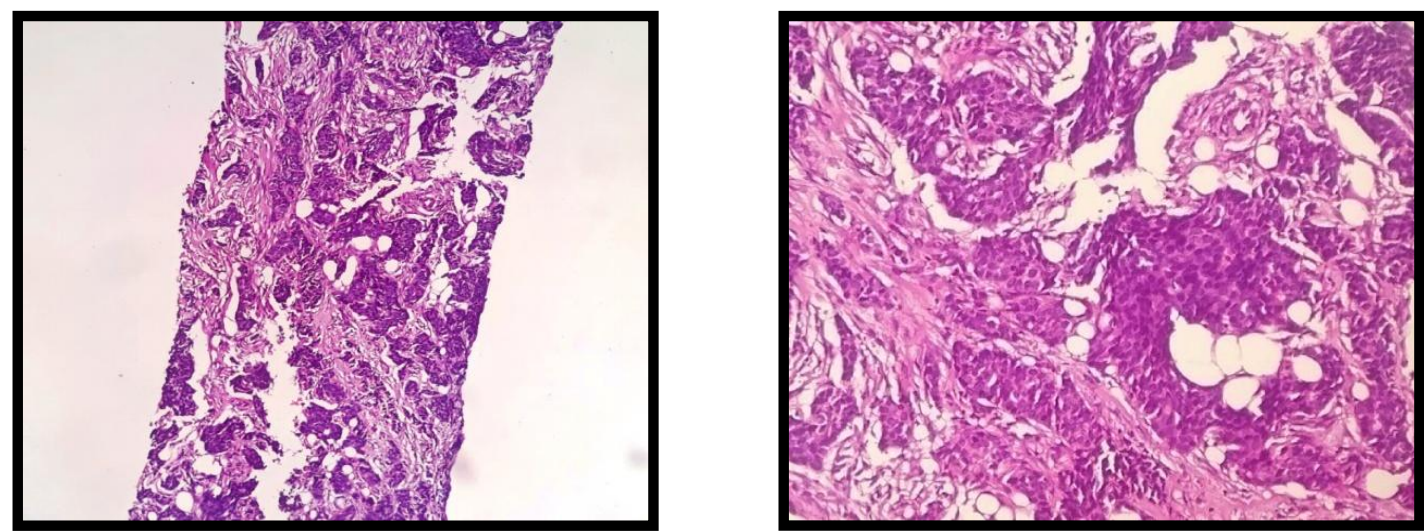

Figure- 8,9 Needle Core Biopsy showing Invasive Breast Carcinoma NST (H\&E stain,100x\&400x)

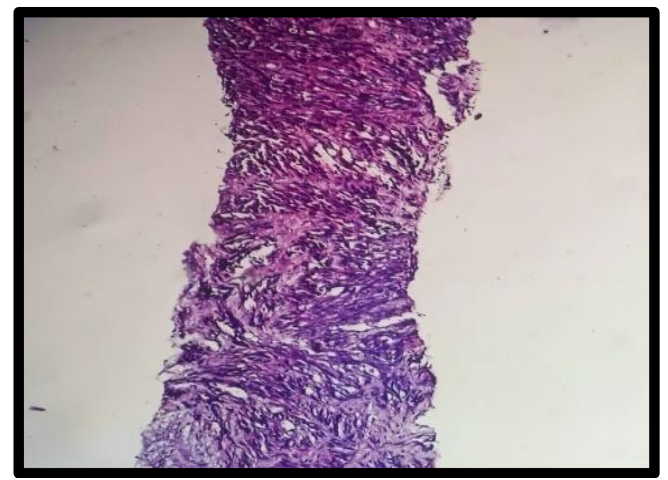

Figure 10 The needle core biopsy shows malignant spindle cells (High Grade) (H\&E stain,100x)

\section{Correlation of Trucut Biopsy and suspicious on Trucut Biopsy findings. The} Histopathological findings

In the present study, Trucut Biopsy findings correlated with the histopathological findings in 103 of 106 cases $(97.2 \%)$, which included 29 of $30(96.7 \%)$ of the benign lesions and 74 of 76 (97.4\%) of the malignant lesions. 1 case was wrongly diagnosed as malignant while one case each was falsely diagnosed as benign and 


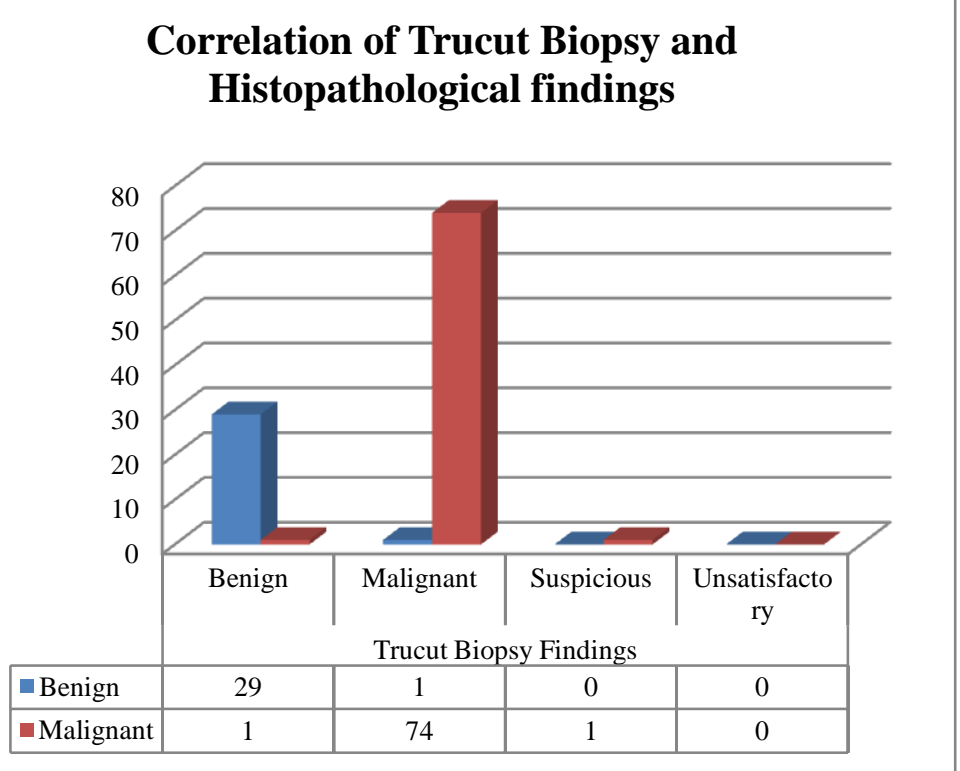

Figure-11 Sensitivity, Specificity, PPV, NPV and Accuracy of Trucut Biopsy

The Sensitivity, Specificity, Positive Predictive Value (PPV) and Negative Predictive Value (NPV) of Trucut Biopsy were 97.37\%, 96.67\%, $98.67 \%$ and $93.55 \%$ respectively. Accuracy of Trucut Biopsy was $97.16 \%$.

\section{Discussion}

In the present study, majority of the patients (30.2\%) were in the age group of 41-50 years followed by $23.6 \%$ in the age group of 51-60 years, $19.8 \%$ in the age group of $31-40$ years, $14.2 \%$ in the age group of $21-30$ years and $12.2 \%$ in the age group of $>60$ years.

Singh $\mathrm{S}$ et $\mathrm{al}^{5}$ did a retrospective study of 104 cases in which 2 patients were Males and rest 102 cases were Females. Age of the patients ranged from 15-65 years with mean age of 33yrs.

It was observed in the present study that out of 106 patients, $15(14.1 \%)$ patients had non neoplastic lesion while 90(85\%) patients had neoplastic lesion Out of 90 neoplastic lesion, 15 $(16.6 \%)$ were benign neoplasm i.e. Fibroadenoma and $75(83.3 \%)$ were malignant. And one case $(0.9 \%)$ was reported as inconclusive/ Suspicious for malignancy.

Similar to present study Samantray S et al ${ }^{6}$ also reported 747 cases $(83.6 \%)$ out of 892 Core biopsies to be diagnosed as malignant Neoplasm.

Ajitha $\mathrm{MB}$ et $\mathrm{al}^{7}$, in a prospective study on fine needle aspiration cytology, trucut biopsy and final histopathological examination in breast lumps found of a total 70 breast lump aspirations, 36 breast lumps were benign and 34 breast lumps were malignant lumps. Of 36 breast lumps with benign lesions, 24(66.6\%) were married.

Rikabi et $\mathrm{al}^{8}$ also reported benign neoplasm to be predominant lesion in their study.

Since the place of our study is tertiary care centre where patient presents with disease in advanced stage, which is the reason for disconcordance with other studies.

In the present study, Trucut Biopsy findings correlated with the histopathological findings in 103 of 106 cases (97.2\%), which included 29 of $30(96.7 \%)$ of the benign lesions and 74 of 76 (97.4\%) of the malignant lesions. 1 case was wrongly diagnosed as malignant while one case each was falsely diagnosed as benign and suspicious on Trucut Biopsy findings. The association was found to be statistically significant $(\mathrm{p}<0.05)$.

Rikabi A et $\mathrm{al}^{8}$ in a cross-sectional study reported final histopathological diagnosis of the TCB specimens, there were $97(35.3 \%)$ true-positive cases, 173 (62.9\%)true-negative cases, 5 (1.8\%) false-negative cases and no false positive cases Dimitrov DD et $\mathrm{al}^{9}$ in a retrospective clinical study reported Histopathology after tru-cut biopsies showed74 (93.7\%) malignant lesions and 5 benign lesions $(6.3 \%)$. Histopathology of the 
post surgical specimen showed 75 (94.9\%) malignant lesions and 4 benign lesions (5.1\%). Comparison of TCB to postsurgical histopathology revealed the following results: 74 true positive cases $(93.7 \%)$, zero false positive cases $(0 \%)$, one false negative case $(1.3 \%)$ and 4 true negative cases $(5.1 \%)$.

The one case falsely diagnosed as benign on trucut biopsy came out to be mucinous carcinoma on histopathology.

Weaver MG et al. ${ }^{10}$ In his study. Mucinous lesion of breast: A pathologic continuum. Reported that The diagnosis of mucinous carcinoma in core needle biopsy is uncomplicated if neoplastic epithelial cells are seen within the mucin. The diagnosis of mucocele like lesion with a frequently minimal epithelial component is more difficult. It is reasonable to view mucocele like lesions as a part of spectrum from benign through to mucinous carcinoma with a significant risk of underdiagnosis from the limited material present on core needle bioplsy. Excision of mucocele like lesions is therefore recommended.

Rosen PP in his study Mucocele like tumors of the breast also reported that Mucocele like lesions must be considered in the differential diagnosis of mucinous carcinoma. ${ }^{11}$
The case falsely diagnosed as malignant on trucut biopsy came out to be Tubular adenosis on histopathology. Patient came for screening mammogram and lump of $1 \mathrm{~cm}$ in size was detected in screening mammography. FNAC of lump was inconclusive and Trucut biopsy was reported B5- positive for low grade malignancy.

Lee $\mathrm{KC}$ et $\mathrm{al}^{12}$ in his study. Tubular Adenosis of the breast- A distinctive benign lesion mimicking invasive carcinoma The histologic hallmark of tubular adenosis is haphazard proliferation of elongated tubules that are non crowded, narrow and sometimes branching. He concluded that tubular adenosis can be potentially mistaken for invasive carcinoma especially when tubular adenosis is cancerized by DCIS.

The case diagnosed as inconclusive was reported as suspicious for malignancy came out to be solid invasive papillary carcinoma on histopathology.

Deshmukh $\mathrm{S}$ et al. ${ }^{13}$ concluded that Papillary carcinoma is the rare entity. differentiation between benign and malignant papillary lesions may be difficult on FNAC as well as trucut biopsy because both procedures targets the centre and invasion is at periphery.

Table 22 Comparison of Studies Conducted to determine the usefulness of Trucut Biopsy in the breast masses.

\begin{tabular}{|c|c|c|c|c|c|}
\hline Author & Senstivity & Specificity & PPV & NPV & $\begin{array}{l}\text { Diagnostic } \\
\text { Accuracy }\end{array}$ \\
\hline Shastri RK et ll $^{14}$ & $95.45 \%$ & $100 \%$ & & & \\
\hline${\text { Dimitrov et } \mathrm{al}^{9}}^{9}$ & $98.67 \%$ & $100 \%$ & $100 \%$ & $80 \%$ & $98.73 \%$ \\
\hline Ajitha $\mathrm{MB}$ et $\mathrm{al}^{\top}$ & $97.14 \%$ & $100 \%$ & $100 \%$ & $97.30 \%$ & \\
\hline Rikabi A et al ${ }^{8}$ & $95.1 \%$ & $100 \%$ & $100 \%$ & $97.2 \%$ & $98.2 \%$ \\
\hline Vega $A$ et $\mathrm{ll}^{15}$ & $90 \%$ & $100 \%$ & & & $91 \%$ \\
\hline Bukhari et al ${ }^{16}$ & $94 \%$ & $100 \%$ & $100 \%$ & $100 \%$ & $89 \%$ \\
\hline Homesh et $\mathrm{al}^{17}$ & $92.3 \%$ & $94.8 \%$ & & & \\
\hline Present study & $97.37 \%$ & $96.67 \%$ & $98.67 \%$ & $93.55 \%$ & $97.16 \%$ \\
\hline
\end{tabular}

\section{References}

1. Florentine BD, Cobb CJ, Frankel K, Greaves T, Martin SE. Core needle biopsy: a useful adjunct to fine-needle aspiration in select patients with palpable breast lesions. Cancer Pathol 1997;81 (1):33-9.
2. Dahlstrom JE, Jain S, Sutton T, Sutton S. Diagnostic accuracy of stereotactic core biopsy in a mammographic breast cancer screening program. Histopathology 1996; 28:421-7. 
3. Pinder SE, Elston CW, Ellis IO. The role of preoperative diagnosis in breast cancer. Histopathology 1996; 28:563- 6.

4. Mikhail RA, Nathan RC, Weiss $M$, Tummala RM,Mullangi UR, Lawrence L,Mukkamala A. Stereotaxic core needle biopsy o.f mammographic breast lesions as a viable alternative to surgical biopsy. Ann Surg Oncol 1994; 1: 363-7.

5. Singh S, Chandra P, Jitendra S. Diagnostic Accuracy of Fine Needle Aspiration Cytology of Breast Lump in Rural Population of Western U.P. Sch. J. App. Med. Sci., 2015; 3(1G):467-469.

6. Samantaray S, Panda N, Besra K, Pattanayak L, Samantara S, Dash S. Utility of Tru-Cut Biopsy of Breast Lesions - An Experience in a Regional Cancer Center of a Developing Country. JCDR;11(3): : EC36 - EC3

7. Ajitha MB, Babu VB and Singh AC. Comparative study of fine needle aspiration cytology, trucut biopsy and final histopathological examination in breast lumps. International Journal of Biomedical Research 2017; 8(03): 154-157.

8. Rikabi A, Hussain S. Diagnostic Usefulness of Tru-Cut Biopsy in the Diagnosis of Breast Lesions. Oman Medical Journal. 2013;28(2):125-127..

9. Dimitrov DD, Karamanliev MP, Deliyski TS, Gabarski AV, Vatov PP, Gencheva Ro, et al. Diagnostic Value Of Tru-Cut Biopsy In Diagnosing Breast Lesions. J Biomed Clin Res. 2016, 9( 2) :126-129.

10. Weaver MG, Abdul Karim FW, al Kaisi N. Mucinous lesion of breast: A pathologic continuum. Pathol Res Pract.1993; 189(8):873-876
11. Rosen PP Mucocele like tumors of the breast. Am J Surg Pathol.1986;10:464-469

12. Lee K, Chan JKG, Gwi E. Tubular adenosis of the breast: a distinctive benign lesion mimicking invasive carcinoma. Am J Surg Pathol 1996;20:46-54.

13. Deshmukh S, Mane A, Hardas V,Karnik S. Papillary Carcinoma of the breast- Case Reports and Review of literature regarding Management guidelines. Indian $\mathrm{J}$ Surg.2012;74(6);510-512.

14. Shastri RK. Fine Needle Aspiration Cytology Verses Trucut Biopsy In Preoperative Planning Of Surgical Treatment Of Breast Lumps. Journal of Dental and Medical Sciences (IOSRDMS). 2016; 15( 7): 74-80

15. Vega A, Garijo F \& Ortega E. Core Needle Aspiration Biopsy of Palpable Breast Masses, Acta Oncologica,1995 34:1, 31-34.

16. Bukhari MH, Akhtar ZM. Comparison of accuracy of diagnostic modalities for evaluation of breast cancer with review of literature. Diagn Cytopathol. 2009;37:41624.

17. Homesh NA, Issa MA, El- Sofiani HA. The diagnostic accuracy of fine needle aspiration cytology versus core needle biopsy for palpable breast lump(s).Saudi Med J 2005; 26(1): 42-46. 